\title{
An ethnopsychological $A B C$ framework of psychiatric morbidity to facilitate psychotherapeutic interventions in Nepal
}

\author{
Dhirendra Paudel ${ }^{1,2}$
}

To cite: Paudel, D. (2021, March 16). An ethnopsychological $A B C$ framework of psychiatric morbidity to facilitate psychotherapeutic interventions in Nepal. https://doi.org/10.31234/ osf.io/2kfsu

Created:

March 17, 2021

Last edited:

March 30, 2021

(c) Author: Creative Commons Attribution 4.0 International Public License

Dhirendra Paudel,

${ }^{1}$ Department of Psychiatry, Dhaulagiri Hospital, Baglung 33300, Gandaki, Nepal.

2 Mental Health and Yoga Pvt Ltd, Pokhara, 33700,

Gandaki, Nepal.

Email:

dhirendra@doctor.com.

Phone:

+9779851178791.

ORCID ID:

0000-0003-3619-9798

Correspondence to Dr Dhirendra Paudel; dhirendra@doctor.com

\section{ABSTRACT}

The coronavirus disease 2019 (COVID-19) pandemic can be overwhelming leading to strong emotions and distress. Most studies reported the impact on mental health due to uncertainty, fear, and anxiety about the pandemic and post pandemic states. The sufferers may present with a variety of symptoms of psychological distress. Failure to communicate this psychosocial distress between lay and health care providers may pose barriers to treatment and challenges for integration of mental health into primary health centers. There is a need for tools to screen and explain pandemic associated distress in a way that attending physician can communicate with laymen in a coherent way. The article introduces an ethnopsychologial $\mathrm{ABC}$ framework that individual in distress can better understand the nature of the illness. Rather than providing a diagnosis to inexperienced clients of psychiatric morbidity, this method promotes improved communication and bridge the observed gaps. Thus, it helps to raise awareness of the relationship between cultural, emotional, thought, behavior, and psychosocial distress. This article discussed the assessment of the ABC framework with ethnopsycholgical premises and psychotherapeutic intervention at different levels that can be applied.

Keywords: Ethnopsychology, ABC, Psychotherapy, Mental Disorders, Psychology.

\section{INTRODUCTION}

On March 11, 2020, the World Health Organization (WHO) declared coronavirus disease 2019 (COVID-19) as pandemic (Arpaci, Karatas, \& Baloglu, 2020). As of January 6, 2021, all 77 districts of Nepal have reported COVID-19 positive with 262,783 confirmed cases and 1,893 deaths (World Health Organization, 10 January, 2021). The pandemic stirs up the crisis in mental health at the individual level (fear, anxiety, phobia, and paranoia) and the societal level (predating vulnerable, discrimination, and stigmatization) (Ian Freckelton, 2020; Mertens, Gerritsen, Duijndam, Salemink, \& Engelhard, 2020). Furthermore, with the crisis, there is an increase in the need for assessment and management of mental health (Ahorsu et al., 2020; Arpaci et al., 2020; Fitzpatrick, Harris, \& Drawve, 2020). However, in Nepal applying western psychotherapeutics practices face several challenges due to the difference in the historical and cultural background of the individual and society (Tol, Jordans, Regmi, \& Sharma, 2005). The ABC model for Rational Emotive Behavior Therapy (REBT) formulated by Albert Ellis and its basic premises were modified for various psychotherapeutic interventions (Ellis, 1994; Field, Beeson, \& Jones, 2015; Sánchez, Coma, Aguelo, \& Cerezo, 2019) and can be used for better communication of the psychosocial distress between lay and health care providers. As the perception of mental illness or stress by Nepalese differs hence the psychotherapeutic interventions and $A B C$ model need better incorporation of the ethnopsychology. As ethnopsychology incorporates tradition, social, and cultural group which conceptualize the self, feelings, human nature, inspiration, identity, and the elucidation of experience and their impact on psyche (Chellappan, 2016; B. A. Kohrt \& Hruschka, 2010). Incorporating ethnopsychology in the $\mathrm{ABC}$ model increases the therapeutic alliance and responsiveness towards psychotherapeutic interventions. And such an $\mathrm{ABC}$ framework encourages individuals and clinicians to communicate the association between adversity, belief, and consequences underpinning distress or struggle where individuals effortlessly .recognize and decipher their symptoms which makes a difference to guide treatment (Turner, 2016). 
Ethnopsychological ABC model of psychiatric morbidity

In the ABC model, (A) denotes activating events (or adversity), (B) symbolizes beliefs about the events that individuals have, and $(\mathrm{C})$ represents consequences which can be emotional, behavioral, and cognitive generated by cognitively processed and evaluated beliefs about adversity (David, Matu, Pintea, Cotet, \& Nagy, 2014; Dryden, 2012; Sánchez et al., 2019). Consequently, the (C) can be an activating agent (A) that generates secondary beliefs or metabeliefs (B) which in turn underpin secondary consequences or meta-consequences (C) (David et al., 2014; Sánchez et al., 2019).

\section{Activating Events (As)}

An activating event is an external event (real-life events) and/ or internal event (inside an individual's mind e.g., memories, dreams, images, etc.). These can be aspects of pandemic and post-pandemic uncertainty. Nepal implemented quarantine measures as well as lockdown during the initial phase to prevent the COVID-19 outbreak (Dhakal \& Karki, 2020) which affected tourism, agriculture, and remittances (Poudel \& Subedi, 2020). Nepal being a low and middle-income county (LMIC), pandemic exacerbates the economic burden on families and the healthcare system (Dhakal \& Karki, 2020; Poudel \& Subedi, 2020). Maintenance treatments of chronic and mental illness were hampered due to restrictions applied and fear of contracting COVID-19(Li et al., 2020). (A) is inferential and individuals may have varied inferences (multiple As) and emotional responses of the life events (Dryden, 2012). The inferential themes prevalent during a pandemic and post pandemic era are frustration, boredom, fear of infection, and stigma (Brooks et al., 2020). Nepalese tends to see the self and emotion encompasses physical body, the brain-mind, the heart-mind, family, social integrity, spirits, spiritual world, and ancestral deities (Brandon A. Kohrt, Maharjan, Timsina, \& Griffith, 2012) plays a dynamic role in the activating event's inferential theme which should be assessed while communicating with the client.

\section{Beliefs (Bs)}

Beliefs include the demands one makes on self, others, and the world, core values, thought patterns, as well as processed and evaluated meaning of the internal and external events. However, there may be disparity but the common sociocultural belief of mental illness in Nepal is connected with spirits that can control an individual by bewitchment or dislodging or possessing soul causing illness (Tol et al., 2005). Besides, one ought to consider the Nepalese notion of the heart-mind which contains worries, traumatic, meddling memories, fear, and anxiety responsible for desires and wishes. The heart-mind is under the brain-mind which is accountable for cognition, attention, and societal concordance. The discoordination between brain-mind and heart-mind yields mental ailment (Brandon A. Kohrt et al., 2012). The idea of emotional distress is mainly generated by the interaction between experienced inference and irrational beliefs of the event. Ensuing to this theme people ought to hold an alternative set of rational beliefs to act soundly to the same event (Dryden, 2012). However, the disputation of beliefs is a challenge while applying to an inexperienced audience.

\section{Consequences (Cs)}

The consequences are emotional, behavioral, and cognition underpinned by belief for inferences of activating events and life experiences (Dryden, 2012). The links between events and distress are negative thoughts in belief systems. However, Nepalese tends to complain about behavioral and emotional consequences with physical symptoms rather than abstract feelings (Brandon A. Kohrt et al., 2012; Tol et al., 2005). Such that difficulties with the heart-mind is expressed with headaches, stomach upset, bodily pain, numbness, and tingling sensations reflecting mood and anxiety disorders while difficulties with the brain-mind exhibit behavioral disturbances such as impulse control disorders, psychosis, and suicides (Brandon A. Kohrt et al., 2012). The pandemic crisis can be precipitating factors for intentional injuries and heavy alcohol use (Lange, Probst, \& Rehm, 2020) due to the easy availability of homebrewed alcohol from barley, rice, or millet in Nepalese households (Pradhan et al., 2015). There was a $20 \%$ increase in suicide in the first month of lockdown and from March 23 to June 6 Nepal reported 1227 suicides (Poudel \& Subedi, 2020).

\section{Discussion and Implications}

Amid the psychological crisis during the pandemic and post pandemic, it is necessary to assess the mental health impact at diverse societal levels, recognize vulnerable populations for violence and suicidality, and deliver essential psychotherapeutic intervention for people in need ( $\mathrm{Li}$ et al., 2020). The Nepalese population has been through the Maoist insurgency and the major earthquake which left Nepalese to predispose and vulnerable to psychological distress (Chase, Sapkota, Crafa, \& Kirmayer, 2018). Pandemic related stress is accelerating and sustaining the distress. Each new case and death within the community brings a new surge of distress. Our health care framework ought to be able to recognize this distress and give essential mental health needs. However, there is a barrier to providing mental health care services due to a lack of uniform communication tools between laypeople and mental health care providers (Keys, Kaiser, Kohrt, Khoury, \& Brewster, 2012). The outline of ethnopsychological concepts of the mind, body, and mental illness in the $\mathrm{ABC}$ framework may provide appropriate clinical language in which inexperienced audiences can understand mental illness. And such it can facilitate understanding of mental disorders, treatment guidance (Turner, 2016), and adherence to therapy.After documenting the ABC framework, the fundamental aim of REBT is 
restructuring the irrational belief with the dispute(D) to generate new effect or efficient(E) alternative rational beliefs which then reduces the negative emotions such as fear, anger, anxiety, and depression in turn generating to facilitate (F) functional consequences (David et al., 2014; Turner, Slater, \& Barker, 2014). The methods commonly applied during the disputation of beliefs are pragmatic (unhelpful or helpful), empirical (false or true), and logical (illogical or logical). During disputation, if the beliefs are illogical, false, and/or unhelpful they are rendered as irrational, and if logical, true, and helpful they are considered rational (David et al., 2014; Turner et al., 2014). However, disputation is difficult with an inexperienced Nepalese audience. Nonetheless, the ABC framework of REBT can be applied without disputing intervention which can be kept in the background for familiar clients (Ruggiero, Sarracino, McMahon, Caselli, \& Sassaroli, 2016). Furthermore, individuals can comprehend the control they have at different levels i.e. (A), (B), and/or (C) of the $\mathrm{ABC}$ framework to act at reducing psychosocial distress. Previous research studies have shown promising outcomes with various specific psychotherapy such as cognitive behavior therapy, dialectical behavior therapy, and interpersonal therapy in Nepal (Brandon A. Kohrt et al., 2012; Rose-Clarke et al., 2020). However, simplifying the complex psychotherapy for inexperienced clients with an emphasis on psychotherapeutic tools and micro-skills such as psychoeducation, relaxation therapy, problem-solving skills, and role-play integrated with the local idiom of distress and culture provides better outcome (Tol et al., 2005). Transcendent bliss from mindfulness, community involvement, and daily worships are protective spiritual and cultural factors for resilience development in Nepal (Chase et al., 2018). Such factors and micro-skills can be applied to the different levels of the ABC framework. Nepal has not only limited resources in mental health care with limited psychologists, psychiatrists, and psychosocial workers but also more efforts are provided by non-governmental organizations (NGOs) than government organizations (Chase et al., 2018). However, for the treatment of mental ailments, most Nepalese still prefer traditional healers (Chase et al., 2018). As traditional healers and paramedics are first to come in contact with clients having a mental disorder. Nepal should proactively incorporate, collaborate, and train available resources like traditional healers and paraprofessionals for mental health care (B. Kohrt et al., 2018; Tol et al., 2005). Mental health Gap Action Program (mhGAP) launched by World Health Organization (WHO) (World Health Organization, 2016) to reduce the treatment gap aim at integrating into primary health care centers is an ongoing and welcoming program in Nepal (M. J. D. Jordans, Luitel, Pokhrel, \& Patel, 2016; Mark J. D. Jordans, Luitel, Tomlinson, \& Komproe, 2013). However biopsychosocialspiritual-cultural assessment can provide more insights into the Nepalese context of psychological distress. The intended application of this concept is to supplement the communication for implementing mhGAP interventions
(World Health Organization, 2016) and incorporate physical, mental, and social suffering concerning cultural differences for holistic methods to well-being. Thus, advancing the global research on mental health priorities (Keys et al., 2012). The exponential outbreak of COVID-19 is bringing uncertainty, anger, fear, anxiety and stress as well as having impact on assessment and management of pre-existing health and mental disorders. It is necessary for every country to take action to mitigate the potential outbreak of mental health pandemic.

\section{Conflicts of interest}

None

Ethics statement

Not Required

\section{References}

Ahorsu, D. K., Lin, C. Y., Imani, V., Saffari, M., Griffiths, M. D., \& Pakpour, A. H. (2020). The Fear of COVID-19 Scale: Development and Initial Validation. Int J Ment Health Addict, 1-9. doi:10.1007/s11469-020-00270-8

Arpaci, I., Karatas, K., \& Baloglu, M. (2020). The development and initial tests for the psychometric properties of the COVID-19 Phobia Scale (C19PS). Pers Individ Dif, 164, 110108. doi:10.1016/j.paid.2020.110108

Brooks, S. K., Webster, R. K., Smith, L. E., Woodland, L., Wessely, S., Greenberg, N., \& Rubin, G. J. (2020). The psychological impact of quarantine and how to reduce it: rapid review of the evidence. The Lancet, 395(10227), 912-920. doi:https://doi.org/10.1016/S0140-6736(20)30460-8

Chase, L. E., Sapkota, R. P., Crafa, D., \& Kirmayer, L. J. (2018). Culture and mental health in Nepal: an interdisciplinary scoping review. Global Mental Health, 5, e36. doi:10.1017/gmh.2018.27

Chellappan, X. (2016). Ethno psychology and its application.Research. Research J. Humanities and Social Sciences, 241-249.

David, O. A., Matu, S. A., Pintea, S., Cotet, C. D., \& Nagy, D. (2014). Cognitive-behavioral processes based on using the ABC analysis by trainees for their personal development. Journal of Rational-Emotive \& CognitiveBehavior Therapy, 32(3), 198-215.

Dhakal, S., \& Karki, S. (2020). Early Epidemiological Features of COVID-19 in Nepal and Public Health Response. Frontiers in Medicine, 7(524). doi:10.3389/fmed.2020.00524

Dryden, W. (2012). The "ABCs" of REBT I: A Preliminary Study of Errors and Confusions in Counselling and Psychotherapy Textbooks. Journal of Rational-Emotive \& Cognitive-Behavior Therapy, 30(3), 133-172. doi:10.1007/s10942-011-0137-1

Ellis, A. (1994). Reason and emotion in psychotherapy : a comprehensive method of treating human disturbances. New York: Carol Publishing Group.

Field, T. A., Beeson, E. T., \& Jones, L. K. (2015). The new ABCs: A practitioner's guide to neuroscience-informed cognitive-behavior therapy. Journal of Mental Health Counseling, 37(3), 206-220. 
Fitzpatrick, K. M., Harris, C., \& Drawve, G. (2020). Fear of COVID-19 and the mental health consequences in America. Psychol Trauma, 12(S1), S17-S21. doi:10.1037/tra0000924

Ian Freckelton, Q. C. (2020). COVID-19: Fear, quackery, false representations and the law. International Journal of Law and Psychiatry, 101611. doi:10.1016/j.ijlp.2020.101611

Jordans, M. J. D., Luitel, N. P., Pokhrel, P., \& Patel, V. (2016). Development and pilot testing of a mental healthcare plan in Nepal. British Journal of Psychiatry, 208(s56), s21-s28. doi:10.1192/ bjp.bp. 114.153718

Jordans, M. J. D., Luitel, N. P., Tomlinson, M., \& Komproe, I. H. (2013). Setting priorities for mental health care in Nepal: a formative study. BMC Psychiatry, 13(1), 332. doi:10.1186/1471-244X-13-332

Keys, H. M., Kaiser, B. N., Kohrt, B. A., Khoury, N. M., \& Brewster, A. R. (2012). Idioms of distress, ethnopsychology, and the clinical encounter in Haiti's Central Plateau. Soc Sci Med, 75(3), 555-564. doi:10.1016/j.socscimed.2012.03.040

Kohrt, B., Asher, L., Bhardwaj, A., Fazel, M., Jordans, M., Mutamba, B., . . Patel, V. (2018). The Role of Communities in Mental Health Care in Low- and Middle-Income Countries: A Meta-Review of Components and Competencies. International Journal of Environmental Research and Public Health, 15(6). doi:10.3390/ijerph15061279

Kohrt, B. A., \& Hruschka, D. J. (2010). Nepali concepts of psychological trauma: the role of idioms of distress, ethnopsychology and ethnophysiology in alleviating suffering and preventing stigma. Cult Med Psychiatry, 34(2), 322-352. doi:10.1007/s11013-010-9170-2

Kohrt, B. A., Maharjan, S. M., Timsina, D., \& Griffith, J. L. (2012). Applying Nepali Ethnopsychology to Psychotherapy for the Treatment of Mental Illness and Prevention of Suicide among Bhutanese Refugees. Annals of Anthropological Practice, 36(1), 88-112. doi:10.1111/ j.2153-9588.2012.01094.x

Lange, S., Probst, C., \& Rehm, J. (2020). Coronavirus disease 2019 crisis and intentional injuries: now is not the time to erode alcohol control policies. Canadian journal of public health $=$ Revue canadienne de sante publique, 111(4), 466-468. doi:10.17269/s41997-020-00391-6

Li, W., Yang, Y., Liu, Z.-H., Zhao, Y.-J., Zhang, Q., Zhang, L., . . . Xiang, Y.-T. (2020). Progression of Mental Health Services during the COVID-19 Outbreak in China. International Journal of Biological Sciences, 16(10), 1732-1738. doi:10.7150/ijbs.45120

Mertens, G., Gerritsen, L., Duijndam, S., Salemink, E., \& Engelhard, I. M. (2020). Fear of the coronavirus (COVID-19): Predictors in an online study conducted in March 2020. Journal of Anxiety Disorders, 74, 102258. doi:https://doi.org/10.1016/j.janxdis.2020.102258

Poudel, K., \& Subedi, P. (2020). Impact of COVID-19 pandemic on socioeconomic and mental health aspects in Nepal. Int J Soc Psychiatry, 0(0), 20764020942247. doi:10.1177/0020764020942247

Pradhan, B., Hadengue, A., Chappuis, F., Chaudhary, S., Baral, D., Gache, P., . . Rijal, S. (2015). Alcoholic liver disease in Nepal: identifying homemade alcohol as a culprit. Clinical and experimental gastroenterology, 8, 183-189. doi:10.2147/CEG.S81321

Rose-Clarke, K., Pradhan, I., Shrestha, P., B.K, P., Magar, J., Luitel, N. P., . . . Verdeli, H. (2020). Culturally and developmentally adapting group interpersonal therapy for adolescents with depression in rural Nepal. BMC Psychology, 8(1), 83. doi:10.1186/s40359-020-00452-y
Rose-Clarke, K., Pradhan, I., Shrestha, P., B.K, P., Magar, J., Luitel, N. P., . . . Verdeli, H. (2020). Culturally and developmentally adapting group interpersonal therapy for adolescents with depression in rural Nepal. BMC Psychology, 8(1), 83. doi:10.1186/s40359-020-00452-y

Ruggiero, G. M., Sarracino, D., McMahon, J., Caselli, G., \& Sassaroli, S. (2016). Practicing REBT in Italy: Cultural Aspects. Journal of Rational-Emotive \& Cognitive-Behavior Therapy, 35(2), 125-135. doi:10.1007/s10942-016-0246-y

Sánchez, Y., Coma, T., Aguelo, A., \& Cerezo, E. (2019). ABCEBDI: An affective framework for BDI agents. Cognitive Systems Research, 58, 195-216. doi:https://doi.org/10.1016/j.cogsys.2019.07.002

Tol, W. A., Jordans, M. J. D., Regmi, S., \& Sharma, B. (2005). Cultural Challenges to Psychosocial Counselling in Nepal.

Transcultural Psychiatry, 42(2), 317-333. doi:10.1177/1363461505052670

Turner, M. J. (2016). Rational Emotive Behavior Therapy (REBT), Irrational and Rational Beliefs, and the Mental Health of Athletes. Frontiers in psychology, 7, 1423-1423. doi:10.3389/fpsyg.2016.01423

Turner, M. J., Slater, M. J., \& Barker, J. B. (2014). Not the End of the World: The Effects of Rational-Emotive Behavior Therapy (REBT) on Irrational Beliefs in Elite Soccer Academy Athletes. Journal of Applied Sport Psychology, 26(2), 144-156. doi:10.1080/10413200.2013.812159

World Health Organization. (10 January, 2021). WHO Nepal Situation Updates on COVID-19. Situation Update \#38. Retrieved from https://www.who.int/docs/default-source/nepal-documents/novelcoronavirus/who-nepal-sitrep/-38_who_nepal_sitrep_covid-19.pdf

World Health Organization. (2016). mhGAP Intervention Guide for Mental, Neurological and Substance Use Disorders in NonSpecialized Health Settings: Mental Health Gap Action Programme (mhGAP): Version 2.0. In. Geneva: World Health Organization. 